\title{
AZD5363 inhibits inflammatory synergy between interleukin-17 and insulin/insulin-like growth factor 1
}

\author{
Chong Chen ${ }^{1,2}$, Qiuyang Zhang ${ }^{1,2}$, Sen Liu 1,2, Mark Lambrechts ${ }^{1,2}$, Yine Qu ${ }^{1,2,3}$ and Zongbing You ${ }^{1,2 *}$ \\ Department of Structural and Cellular Biology, Tulane Cancer Center and Louisiana Cancer Research Consortium, Tulane Center for Stem Cell Research and \\ Regenerative Medicine, Tulane Center for Aging, Tulane University School of Medicine, New Orleans, LA, USA \\ ${ }^{2}$ Department of Orthopaedic Surgery, Tulane Cancer Center and Louisiana Cancer Research Consortium, Tulane Center for Stem Cell Research and Regenerative \\ Medicine, Tulane Center for Aging, Tulane University School of Medicine, New Orleans, LA, USA \\ ${ }^{3}$ Department of Histology and Embryology, Hebei United University School of Basic Medicine, Tangshan, Hebei Province, China
}

\section{Edited by:}

Gyu Seog Choi, Kyungpook National

University Medical Center, South

Korea

\section{Reviewed by:}

Jennifer Wu, Medical University of South Carolina, USA

Chang-Deng Hu, Purdue University, USA

\section{*Correspondence:}

Zongbing You, Department of

Structural and Cellular Biology, Tulane University School of Medicine, 1430

Tulane Avenue Mailbox 8649, New

Orleans, LA 70112, USA

e-mail: zyou@tulane.edu
In the United States, one-third of population is affected by obesity and almost 29 million people are suffering from type 2 diabetes. Obese people have elevated serum levels of insulin, insulin-like growth factor 1 (IGF1), and interleukin-17 (IL-17). Insulin and IGF1 are known to enhance IL-17-induced expression of inflammatory cytokines and chemokines, which may contribute to the chronic inflammatory status observed in obese people. We have previously demonstrated that insulin/IGF1 signaling pathway crosstalks with IL-17-activated nuclear factor-kB pathway through inhibiting glycogen synthase kinase $3 \beta$ (GSK3 $\beta$ ) activity. However, it is unclear whether GSK3 $\alpha$ also plays a role and whether this crosstalk can be manipulated by AZD5363, a novel pan-Akt inhibitor that has been shown to increase glycogen synthase kinase 3 activity through reducing phosphorylation of GSK3 $\alpha$ and GSK3 3 . In this study, we investigated IL-17-induced expression of C-X-C motif ligand 1 ( $C x C / 1), C-$ C motif ligand 20 (Cc/20), and interleukin-6 (II-6) in wild-type, GSK3 $\alpha^{-/-}$, and GSK3 $\beta^{-/-}$ mouse embryonic fibroblast cells as well as in mouse prostate tissues by real-time quantitative PCR. We examined the proteins involved in the signaling pathways by Western blot analysis. We found that insulin and IGF1 enhanced IL-17-induced expression of CXC/1, Cc/20, and II-6, which was associated with increased phosphorylation of GSK3 $\alpha$ and GSK3 $\beta$ in the presence of insulin and IGF1. AZD5363 inhibited the synergy between IL-17 and insulin/IGF1 through reducing phosphorylation of GSK3 $\alpha$ and GSK3 $\beta$ by inhibiting Akt function. These findings imply that the cooperative crosstalk of IL-17 and insulin/IGF1 in initiating inflammatory responses may be alleviated by AZD5363.

Keywords: IL-17, insulin, IGF1, inflammation, prostate cancer, obesity

\section{INTRODUCTION}

Interleukin-17 (IL-17 or IL-17A) is an inflammatory cytokine

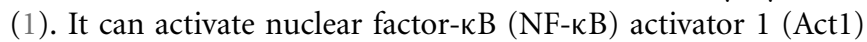
through similar expression to fibroblast growth factor genes, IL17 receptors, and Toll-IL-1R (SEFIR) domains, upon its binding to a heterodimer of IL-17RA/IL-17RC receptor complex (2-6). Act1, as an E3 ubiquitin ligase, activates tumor necrosis factor receptor-associated factor 6 (TRAF6) through lysine-63-linked

Abbreviations: Act1, NF- $\mathrm{KB}$ activator 1; ASF, alternative splicing factor; CCL2, C-C motif ligand 2; Ccl20, C-C motif ligand 20; CCL7, C-C motif ligand 7; cDNA, complementary deoxyribonucleic acid; C/EBP $\beta$, CAAT enhancer binding protein $\beta$; Cxcl1, C-X-C motif ligand 1; CXCL5, C-X-C motif ligand 5; DMEM, Dulbecco's modified eagle's medium; Gapdh, glyceraldehyde-3-phosphate dehydrogenase; GSK, glycogen synthase kinase; IGF1, insulin-like growth factor 1; IGF1R, insulin-like growth factor 1 receptor; IKK, IKB kinase; IL-6, interleukin-6; IL-17, interleukin-17; IL-17R, interleukin-17 receptor; IR, insulin receptor; IRS, insulin receptor substrates; MEF, mouse embryonic fibroblast; mTORC2, mTor complex

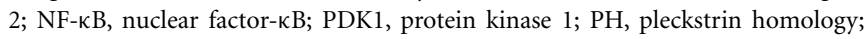
PI3K, phosphatidylinositol 3-kinase; SF2, splicing factor 2; SEFIR, similar expression to fibroblast growth factor genes, IL-17 receptors, and Toll-IL-1R; TAK1, transforming growth factor- $\beta$-activated kinase 1; TRAF6, tumor necrosis factor receptor-associated factor 6 . ubiquitination (7). The polyubiquitinated TRAF6 triggers transforming growth factor- $\beta$-activated kinase 1 (TAK1) and subsequently IкB kinase (IKK) complex, which in turn leads to activation of NF- $\mathrm{KB}$ pathway that induces transcription of a variety of cytokines, chemokines, and growth factor, e.g., C-X-C motif ligand 1 (Cxcl1) and IL-6 (8-10). Several studies have demonstrated that IL-17 stabilizes downstream Cxcll mRNA through an inducible kinase IKKi-dependent Act1-TRAF2-TRAF5 complex, which ligands with splicing factor 2 [SF2, also named alternative splicing factor (ASF)] and prevents SF2/ASF-mediated mRNA degradation $(11,12)$.

Insulin is a hormone produced by the pancreas $\beta$ cells, and its abnormal high concentration (hyperinsulinemia) may circulate in the body of people with obesity and type 2 diabetes mellitus with insulin resistance. Under hyperinsulinemic conditions, the liver produces insulin-like growth factor 1 (IGF1) (13). Two types of insulin receptors (IR-A and IR-B) can bind to either insulin or IGF1. IGF1 can also bind to a heterodimer of IR and IGF1 receptor (IGF1R). Upon binding with the receptors, insulin (or IGF1) leads to autophosphorylation of the $\beta$ subunit of IR or IGF1R (14), which in turn recruits insulin receptor substrates-1 (IRS-1) 
to IRS4, and then phosphatidylinositol 3-kinase (PI3K)/Akt pathway is activated (8). One of the major substrates of Akt is glycogen synthase kinase $3 \beta$ (GSK3 $\beta)(8,15)$. Previous studies have shown that insulin inactivates GSK3 $\beta$ by inducing phosphorylation at serine 9 mainly via Akt signaling pathway $(15,16)$.

Glycogen synthase kinase 3 includes two type of isoforms GSK3 $\alpha$ and GSK3 $\beta$, which are ubiquitously expressed in all cells and capable of phosphorylating more than 50 substrates (17). One of the substrates, CAAT enhancer binding protein $\beta$ $(\mathrm{C} / \mathrm{EBP} \beta)$, is also induced by $\operatorname{IL}-17(3,9,18)$. C/EBP $\beta$ transcription factor is essential for transcription of IL-17 downstream target genes such as IL-6 and 24p3/lipocalin 2 (19). Phosphorylation of C/EBP $\beta$ inhibits expression of IL-17 downstream target genes, thus GSK3 $\beta$ negatively regulates IL-17 signaling through phosphorylation of C/EBP $\beta$ (20). Indeed, inhibition of glycogen synthase kinase 3 (GSK3) activity by GSK3 inhibitor can enhance IL-17-induced expression of IL-6, 24p3/lipocalin 2, CXCL5, C-C motif ligand 2 (CCL2), CCL7, and NF- $\kappa$ B inhibitor zeta, whereas, overexpression of GSK3 $\beta$ can inhibit IL-17-induced IL-6 promoter and 24p3 promoter activities in a mouse stromal ST2 cell line (21). Therefore, GSK3 $\beta$ functions as an intrinsic negative regulator of IL-17-mediated inflammatory responses (21). Our previous study has shown that GSK3 $\beta$ inhibition by phosphorylation or gene knockout enhanced IL-17-induced expression of inflammatory cytokines and chemokines (8).

AZD5363 [(S)-4-amino- $N$-[1-(4-chlorophenyl)-3-hydroxypro pyl]-1-(7H-pyrrolo [2, 3-d] pyrimidin-4-yl) piperidine-4carboxamide] is a pan-Akt inhibitor that is currently being investigated in phase I clinical trials for cancer therapy $(22,23)$. Akt is a serine/threonine protein kinase, also known as protein kinase $\mathrm{B}(\mathrm{PKB})$, which regulates a variety of cellular process including cell proliferation, cell survival, and glucose and fatty acid metabolism (24-26). Because Akt signaling network is the key pro-tumor network in human cancers, it is a target in development of new therapies (27). The active form of Akt is phosphorylated Akt (P-Akt), which may occur at threonine 308 (Thr308) residue phosphorylated by 3-phosphoinositide dependent protein kinase 1 (PDK1), or at serine 473 (Ser 473) residue phosphorylated by mTor complex 2 (mTORC2) (28-30). Given that GSK3 is a downstream substrate of Akt, we hypothesized that inhibition of Akt by AZD5363 might inhibit the synergistic effects between IL-17 and insulin/IGF1. In this study, we tested this hypothesis.

\section{MATERIALS AND METHODS \\ CELLS AND TISSUE CULTURE}

Mouse embryonic fibroblast cells (wild-type, GSK $3 \alpha^{-1-}$, or GSk $3 \beta^{-1-}$ gene knockout) (31) were maintained in a $37^{\circ} \mathrm{C}, 5 \%$ $\mathrm{CO}_{2}$ humidified incubator. All of these cell lines express IL17 receptors A and C (data not shown). Dulbecco's Modified Eagle's Medium (DMEM; Mediatech, Inc., Manassas, VA, USA) with $10 \%$ fetal bovine serum (FBS; Mediatech, Inc.) and 1\% penicillin/streptomycin was used as the growth medium. Mouse prostate tissues were dissected from 7 to 9-week-old male mice euthanized by $\mathrm{CO}_{2}$ asphyxiation. The prostate tissues were washed three times with phosphate-buffered saline (PBS), cut into 1$2 \mathrm{~mm}^{3}$ cubes, and kept in 60-mm cell culture dishes in serum-free
DMEM in the incubator. The animal study was approved by the Animal Care and Use Committee of Tulane University.

\section{TREATMENT OF CELLS AND TISSUES}

Mouse embryonic fibroblast cells were seeded into 60- $\mathrm{mm}$ cell culture dishes with $0.5 \times 10^{6}$ cells/dish. After $24 \mathrm{~h}$ incubation, the cells were incubated with serum-free DMEM for $20 \mathrm{~h}$, and then treated with IL-17 (R\&D Systems, Inc., Minneapolis, MN, USA), insulin, IGF1 (Sigma Aldrich, Inc., St Louis, MO, USA), and/or AZD5363 (Selleck Chemicals, Inc., Houston, TX, USA). The harvested mouse prostate tissues immersed in serum-free DMEM were incubated for $20 \mathrm{~h}$ before any treatments. The treatment for cells and tissues included: (1) control with vehicle; (2) AZD5363 at $2 \mu \mathrm{M}$ for $3 \mathrm{~h}$; (3) insulin at $50 \mathrm{ng} / \mathrm{ml}$ for $2.5 \mathrm{~h}$; (4) IGF1 at $50 \mathrm{ng} / \mathrm{ml}$ for $2.5 \mathrm{~h}$; (5) IL- 17 at $20 \mathrm{ng} / \mathrm{ml}$ for $2 \mathrm{~h}$; (6) insulin + IL-17 at the same doses but adding insulin $0.5 \mathrm{~h}$ before addition of IL-17; (7) IGF1 + IL-17 at the same doses but adding IGF1 $0.5 \mathrm{~h}$ before addition of IL17; (8) AZD5363 + Insulin + IL-17 at the same doses but adding AZD5363 $1 \mathrm{~h}$ and insulin $0.5 \mathrm{~h}$ before addition of IL-17; and (9) AZD5363 + IGF1 + IL-17 at the same doses but adding AZD5363 $1 \mathrm{~h}$ and IGF1 $0.5 \mathrm{~h}$ before addition of IL-17.

\section{REAL-TIME QUANTITATIVE REVERSE TRANSCRIPTASE PCR}

Following treatments, mouse embryonic fibroblast (MEF) cells or mouse prostate tissues were collected in lysis buffer. Mouse prostate tissues were homogenized with Fisher Scientific ${ }^{\mathrm{TM}}$ Model 505 sonic dismembrator. Total RNAs of MEF cells or mouse prostate tissues were isolated by using RNeasy Kit (QIAGEN, Valencia, CA, USA) according to the manufacturer's instructions. Genomic DNA contamination of each sample was avoided by using DNase I digestion. RNA was reversed to cDNA by using iScript ${ }^{\mathrm{TM}}$ cDNA synthesis kit (Bio-rad Laboratories, Hercules, CA, USA). Mouse glyceraldehyde-3-phosphate dehydrogenase (Gapdh), Cxcl1, Ccl20, and Il-6 primers were obtained from Eurofins (Huntsville, AL, USA). The PCR primers specific for each gene were as follows: Cxcl1 forward: 5' CACCCAAACCGAAGTCATAG-3', reverse: 5'-AAGCCAGCGTT CACCAGA-3'; Ccl20 forward: 5'-AACTGGGTGAAAAGGGCT GT-3', reverse: 5'-GTCCAATTCCATCCCAAAAA-3'; Il-6 forward: 5'-CTACCCCAATTTCCAATGCT-3' ${ }^{\prime}$, reverse: $5^{\prime}$-ACCACAG TGAGGAATGTCCA-3'; Gapdh forward: 5'-TGCACCACCAAC TGCTTAG-3', reverse: $5^{\prime}$-GGATGCAGGGATGATGTTC-3'. Quantitative real-time PCR (qRT-PCR) was conducted using iQ5 ${ }^{\circledR}$ iCycler and $\mathrm{iQ}^{\mathrm{TM}}$ SYBR Green Supermix (Bio-Rad Laboratories) following the manufacturer's protocols. The result of each group was normalized to its own Gapdh level by using the formula $\Delta \mathrm{Ct}$ (Cycle threshold $)=\mathrm{Ct}$ of target gene $-\mathrm{Ct}$ of Gapdh. The fold change of mRNA level of each treatment group was calculated as: $\Delta \Delta \mathrm{Ct}=\Delta \mathrm{Ct}$ of target gene in the treatment group $-\Delta \mathrm{Ct}$ of target gene in control group, and fold change $=2^{-\Delta \Delta \mathrm{Ct}}$.

\section{WESTERN BLOT ANALYSIS}

Following the treatment of cells or tissues, proteins were extracted by using RIPA lysis buffer, which contains $50 \mathrm{mM}$ sodium fluoride, $0.5 \%$ Igepal CA-630 (NP-40), $10 \mathrm{mM}$ sodium phosphate, $150 \mathrm{mM}$ sodium chloride, $25 \mathrm{mM}$ Tris ( $\mathrm{pH} 8.0$ ), $1 \mathrm{mM}$ phenylmethylsulfonyl fluoride, $2 \mathrm{mM}$ ethylenediaminetetraacetic 
acid (EDTA), and 1.2 mM sodium vanadate. Protein concentration was assessed by using Bio-Rad Protein Assay Dye Reagent Concentrate (Bio-Rad Laboratories, Hercules, CA, USA) and BioTek ELx800 microplate reader (BioTek, Winooski, VT, USA). Eighty microgram of protein of each group was loaded to $10 \%$ SDS-polyacrylamide gel electrophoresis and transferred to polyvinylidene difluoride membrane. Membrane blocking was done using 5\% non-fat dry milk in TBST buffer $(25 \mathrm{mM}$ Tris$\mathrm{HCl}, 125 \mathrm{mM}$ sodium chloride, and $0.1 \%$ Tween 20). Primary antibody was incubated with the membrane at $4^{\circ} \mathrm{C}$ overnight. The membrane was washed three times with TBST, and incubated with IRDye ${ }^{\circledR} 800 \mathrm{CW}$ - or IRDye ${ }^{\circledR} 680 \mathrm{RD}$-conjugated secondary antibodies (LI-COR Biosciences, Lincoln, NE, USA) at room temperature for $1 \mathrm{~h}$. The membrane was scanned by Odyssey Infrared Imager (LI-COR Biosciences) for visualization. The antibodies used included: rabbit anti-P-Akt (S473), rabbit anti-Akt, rabbit anti-P-GSK3 $\alpha$ (S21), rabbit anti-GSK3 $\alpha$, rabbit anti-P-GSK3 $\beta$ (S9), and rabbit anti-GSK3 $\beta$ antibodies were purchased from Cell Signaling Technology, Danvers, MA, USA. Mouse anti-GAPDH antibody was purchased from Millipore, Billerica, MA, USA.

\section{STATISTICAL ANALYSIS}

The data were presented as mean $\pm \mathrm{SD}$ of triplicate experiments $(n=3)$. Statistical significance was determined by one-way ANOVA and Tukey's tests. All of the analyses were performed using GraphPad Prism ${ }^{\circledR}$ 5.0 (GraphPad Software, La Jolla, CA, USA).

\section{RESULTS}

In the wild-type MEF cells, insulin or IGF1 alone treatment led to increased levels of P-Akt, P-GSK3 $\alpha$, and P-GSK3 $\beta$ (Figures 1A,B). When AZD5363 treatment was added, the levels of P-Akt were further increased. On the contrary, AZD5363 treatment reduced the levels of P-GSK3 $\alpha$ and P-GSK3 $\beta$ (Figures 1A,B). In the GSK $3 \alpha^{-1-}$ MEF cells (Figures 1C,D) and GSK3 $\beta^{-1-}$ MEF cells (Figures 1E,F), insulin or IGF1 alone treatment increased the levels of P-Akt, and subsequently the levels of P-GSK3 $\beta$ and P-GSK3 $\alpha$ in GSK $3 \alpha^{-1-}$ and GSK3 $\beta^{-1-}$ MEF cells, respectively. AZD5363 treatment led to a further increase of P-Akt compared to insulin or IGF1 alone treatment in both GSK $3 \alpha^{-1-}$ and GSK $3 \beta^{-1-} \mathrm{MEF}$ cells. However, AZD5363 treatment reduced the levels of P-GSK3 $\beta$ and P-GSK $3 \alpha$ in GSK $3 \alpha^{-1-}$ and GSK3 $\beta^{-1-}$ MEF cells, respectively, in comparison to insulin or IGF1 alone treatment.

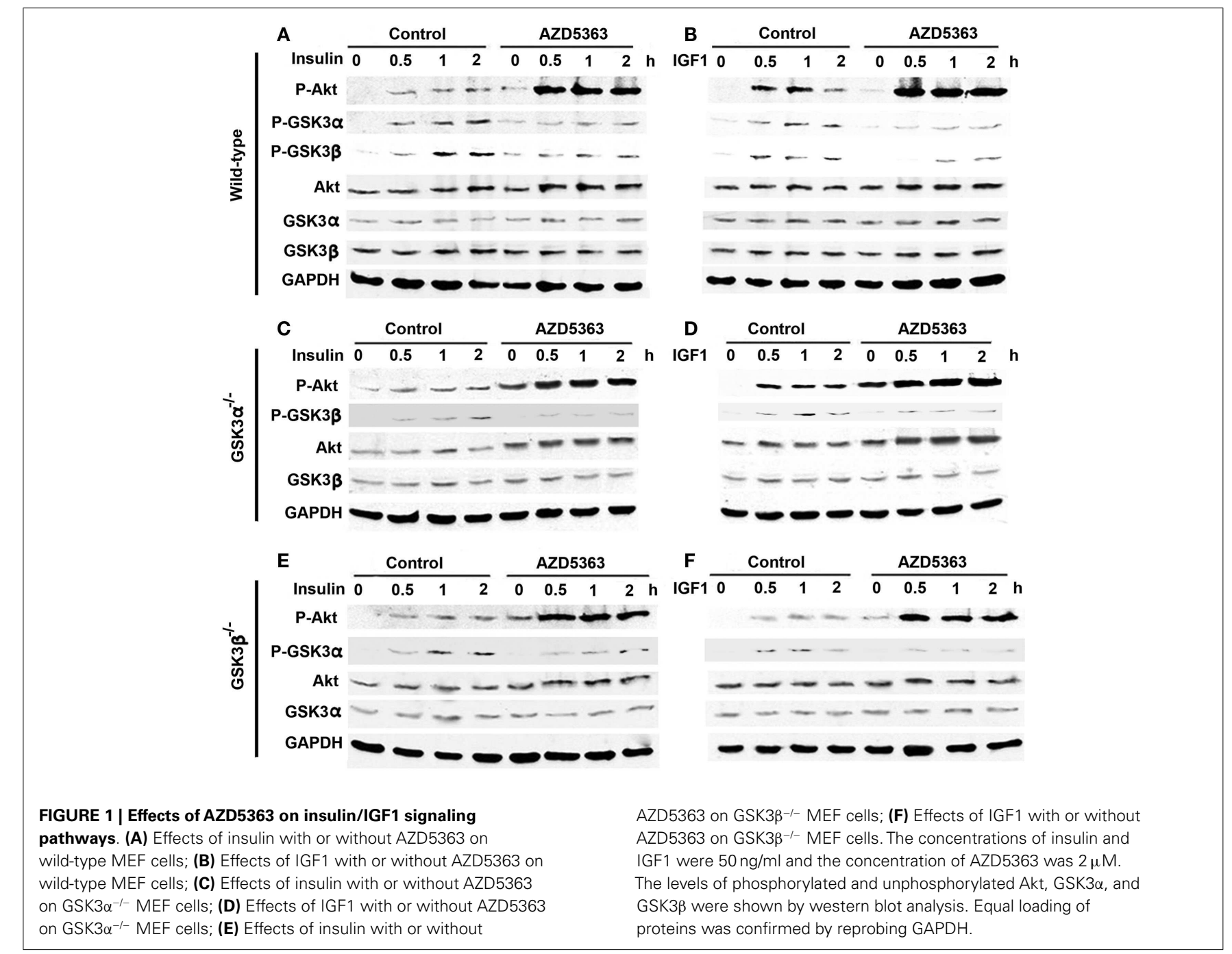



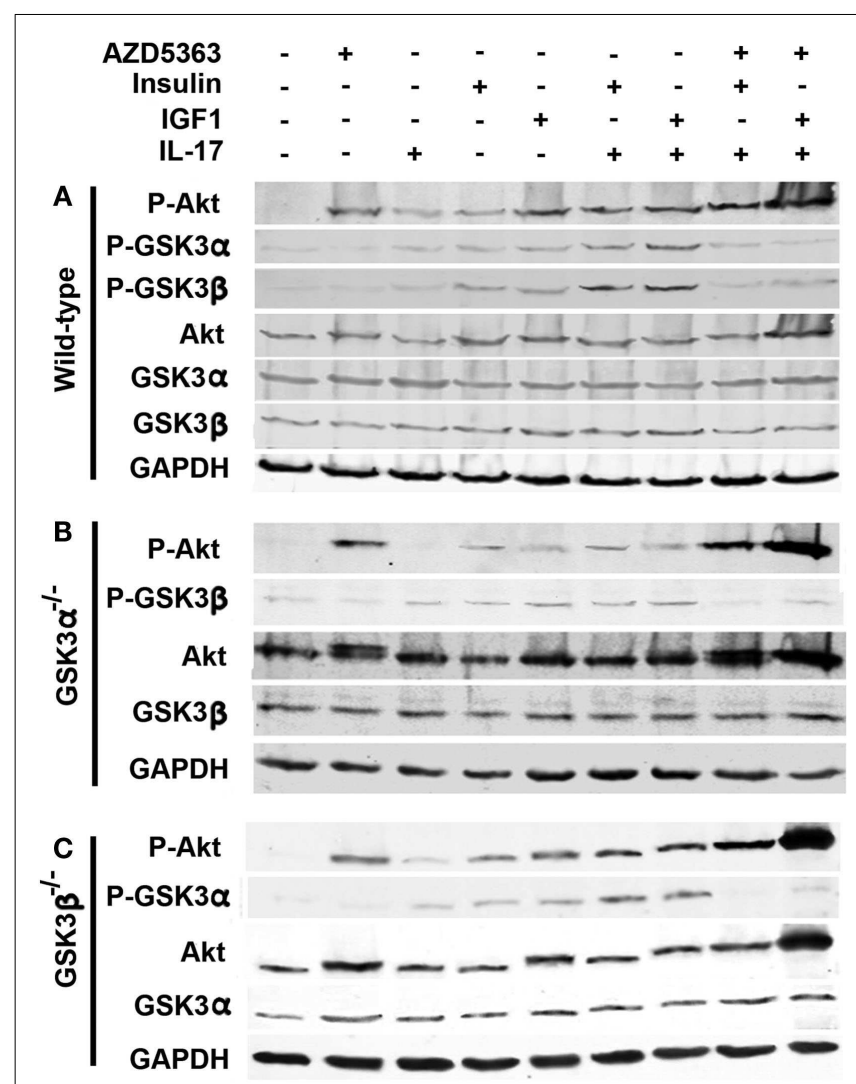

FIGURE 2 | Effects of AZD5363 on IL-17 and insulin/IGF1 signaling pathways in wild-type MEF cells (A), GSK3 $\alpha^{-1-}$ MEF cells (B), and GSK3 $\beta^{-1-}$ MEF cells (C). Cells were treated with $20 \mathrm{ng} / \mathrm{ml} \mathrm{IL-17,50} \mathrm{ng/ml}$

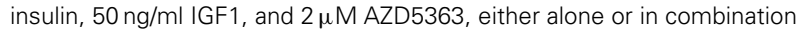
for $2 \mathrm{~h}$. The levels of phosphorylated and unphosphorylated Akt, GSK3 $\alpha$, and GSK3 $\beta$ were shown by western blot analysis. Equal loading of proteins was confirmed by reprobing GAPDH.

As shown in Figure 2A, IL-17, insulin or IGF1 alone treatment only slightly increased the levels of P-Akt, P-GSK3 $\alpha$, and P-GSK3 $\beta$ in wild-type MEF cells, compared to control group. A combination of insulin and IL-17, or IGF1 and IL-17, further increased the levels of P-Akt, P-GSK3 $\alpha$, and P-GSK3 $\beta$. When AZD5363 treatment was added to the combined treatment groups, the levels of P-GSK $3 \alpha$ and P-GSK3 $\beta$ were dramatically reduced, though the levels of P-Akt were further increased. In GSK $3 \alpha^{-1-}$ and GSK3 $\beta^{-1-}$ MEF cells, similar changes were observed, except that only GSK3 $\beta$ (Figure 2B) or GSK3 $\alpha$ (Figure 2C) was present due to knockout of the other GSK3 isoform.

Because AZD5363 treatment decreased the levels of P-GSK3 $\alpha$ and P-GSK3 $\beta$ that might affect IL-17-induced gene expression (8), we checked the mRNA levels of Cxcll and Ccl20 in wildtype, GSK $3 \alpha^{-1-}$ and GSK3 $3 \beta^{-1-}$ MEF cells after the treatment as described above. In the wild-type MEF cells, IL-17 or insulin alone treatment increased Cxcl1 mRNA levels by $2.0 \pm 0.4$ or $1.6 \pm 0.8$ fold, compared to control group (Figure 3A). Cxcl1 mRNA level was increased by $4.6 \pm 0.6$-fold in the insulin and IL-17 combined treatment group, which was statistically significant compared to insulin or IL-17 alone treatment group $(p<0.05)$. Addition of AZD5363 to this combined treatment group reduced Cxcl1 mRNA level to $1.8 \pm 0.1$-fold, which was significantly less than the insulin and IL-17 combined treatment group (Figure 3A, $p<0.05$ ). Similarly, Ccl 20 mRNA levels were increased by $2.0 \pm 0.5$ and $1.6 \pm 0.3$-fold in IL-17 or insulin alone treated group, respectively. A combination of insulin and IL-17 treatment increased Ccl20 mRNA level by $3.0 \pm 0.8$-fold, which was significantly higher than either IL-17 or insulin alone treatment. In contrast, addition of AZD5363 to the combined treatment reduced Ccl20 mRNA level almost to the basal level of $1.1 \pm 0.3$-fold, which was significantly lower than the insulin and IL-17 combined treatment group (Figure 3A, $p<0.05$ ). As shown in Figure 3B, IGF1 and IL-17 also synergistically induced Cxcl1 and Ccl20 mRNA expression, which was inhibited by addition of AZD5363. In GSK3 $\alpha^{-1-}$ (Figures 3C,D) and GSK3 $\beta^{-1-}$ (Figures 3E,F) MEF cells, IL-17 alone treatment dramatically increased the levels of Cxcl1 and Ccl20 mRNA. In contrast to wild-type MEF cells, combination of insulin or IGF1 with IL-17 did not further increase levels of Cxcl1 and Ccl20 mRNA, compared to IL-17 alone treatment (Figures 3C-F). Furthermore, addition of AZD5363 to the combined treatment did not reduce the elevated mRNA levels of Cxcl1 or Ccl20 (Figures 3C-F).

In order to assess if our findings in the studies of cell lines are relevant to the in vivo organ tissues, we did similar experiments using ex vivo cultured mouse prostate tissues. As shown in Figure 4A, increased levels of P-Akt, P-GSK3 $\alpha$, and P-GSK3 $\beta$ were observed in mouse prostate tissues treated with insulin alone, IGF1 alone, a combination of insulin and IL-17, and a combination of IGF1 and IL-17, compared to the control group. However, addition of AZD5363 to the combined treatment groups reduced the levels of P-GSK3 $\alpha$ and P-GSK3 $\beta$, compared to the combined treatment groups. The changes in the signaling proteins were associated with the changes in the mRNA levels of Cxcl1, Ccl20, and Il-6. As shown in Figure 4B, a combination of insulin and IL17 treatment significantly increased the mRNA levels of Cxcl1, Ccl20, and Il-6, compared to insulin or IL-17 alone treatment $(p<0.05)$. Similarly, a combination of IGF1 and IL-17 treatment showed the same effects (Figure 4C). However, when AZD5363 was added to the combined treatment groups, the induction of mRNA levels of Cxcl1, Ccl20, and Il-6 was significantly reduced, compared to the combined treatment groups without AZD5363 (Figures 4B,C).

\section{DISCUSSION}

Inflammation has been shown to be a driving force behind a variety of cancer types (32-34). IL-17 is an inflammatory cytokine that stimulates leukocytes, fibroblasts, epithelial cells, and endothelial cells to release inflammatory signals that can further fire up inflammation (1). We have previously demonstrated that IL-17 promotes formation and growth of prostate cancer in a mouse model (35, 36). Recently, we showed that insulin and IGF1 enhance IL-17induced expression of inflammatory cytokines and chemokines (8). The crosstalk between insulin/IGF1 signaling pathway and IL-17 signaling pathway is mediated by GSK $3 \beta$, as GSK $3 \beta$ knockout blocks the crosstalk. In the present study, we found that GSK3 $\alpha$ 


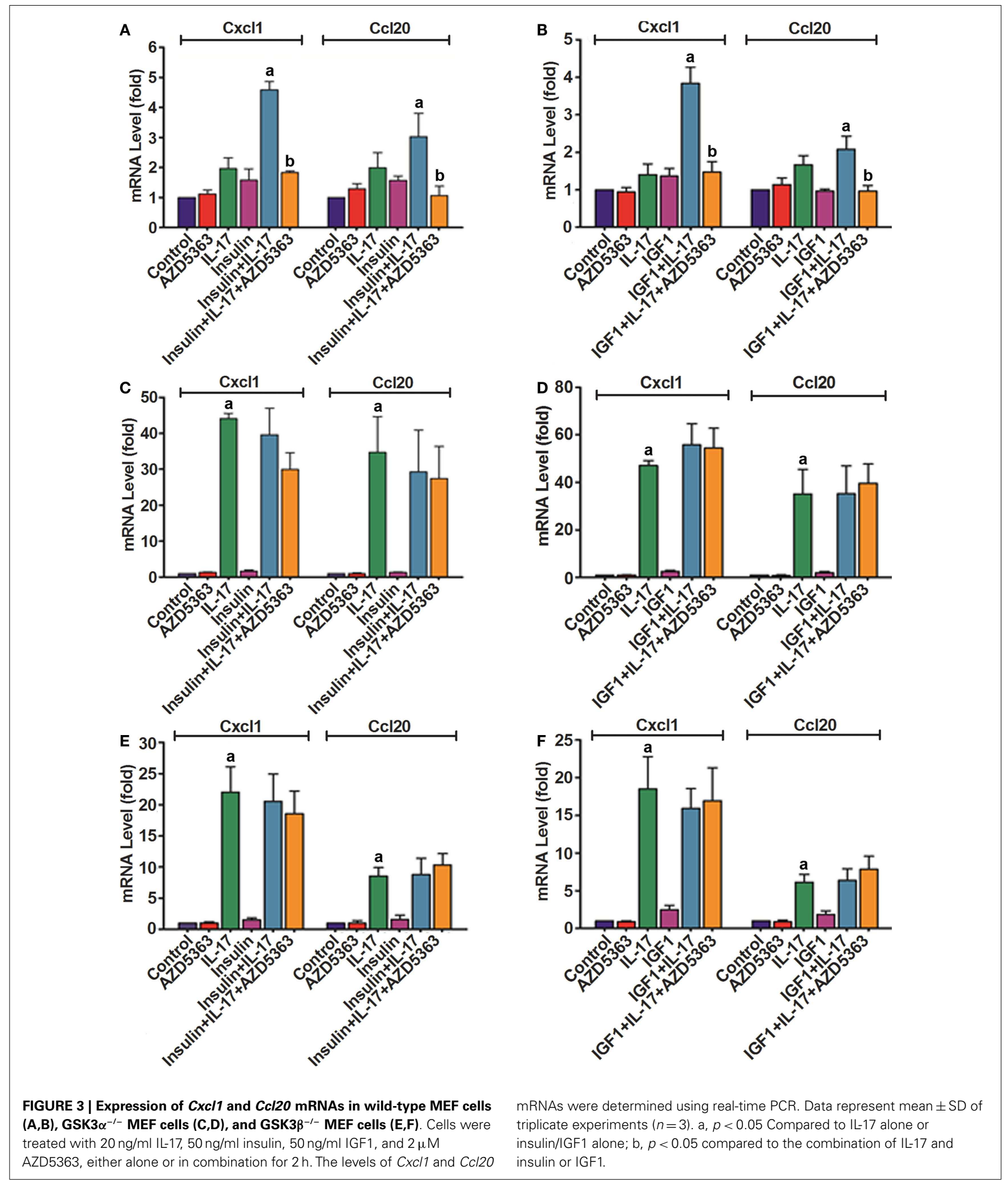

knockout also blocks the crosstalk between insulin/IGF1 and IL17 pathways. In fact, knockout of either GSK3 $\alpha$ or GSK3 $\beta$ appears to relieve the repressive function of GSK3 on IL-17-induced gene expression, as IL-17 can induce gene expression to the levels significantly higher than in the wild-type MEFs where IL-17 can usually induce gene expression to very modest levels. These findings 


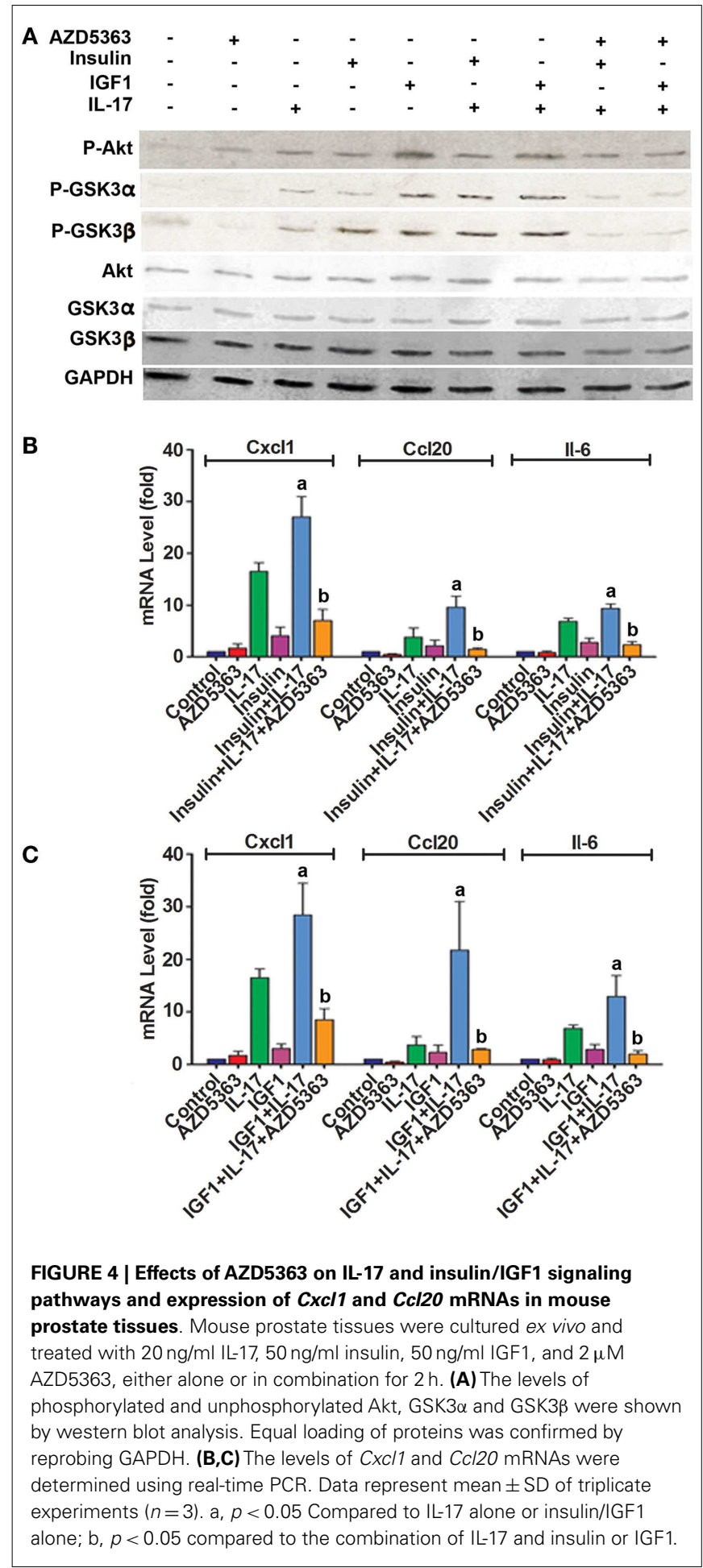

suggest that both GSK3 $\alpha$ and GSK3 $\beta$ isoforms are required to be present, in order to repress IL-17-induced gene expression. Lithium chloride is an inhibitor to both GSK3 $\alpha$ and GSK3 $\beta$ isoforms, which has been shown to increase IL-17-induced gene expression in two previous studies $(8,20)$. The exact molecular mechanisms underlying the crosstalk are yet to be determined,

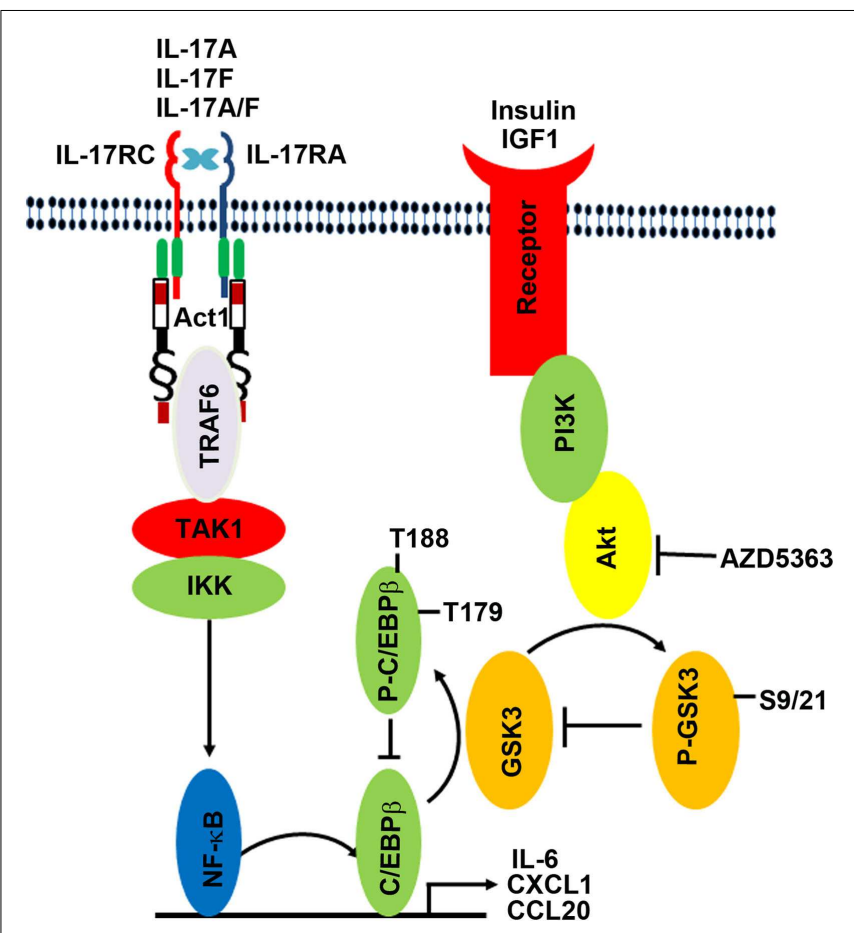

FIGURE 5 | Illustration of the proposed crosstalk between insulin/IGF1 and IL-17 signaling pathways. IL-17 acts through the IL-17RA:IL-17RC receptor complex to activate Act1-TRAF6-TAK1-IKK signaling cascade, thus activating NF-KB transcription factor and subsequently activating $\mathrm{C} / \mathrm{EBP} \beta$ transcription factors. NF- $\mathrm{KB}$ and $\mathrm{C} / \mathrm{EBP} \beta$ transcription factors are required for initiation of transcription of the downstream target genes such as IL-6, $\mathrm{CxCl1}$, and $\mathrm{CCl} 20$. Insulin and IGF1 bind to their receptors and activate PI3K/Akt pathway; Akt phosphorylates GSK3B at serine 9 and GSK3A at serine 21 to inhibit GSK3 activity; GSK3 phosphorylates C/EBP $\beta$ at threonine 179 after a priming phosphorylation at threonine 188 by ERK1/2, thus inhibiting C/EBP $\beta$ 's transcription function. Therefore, insulin/IGF1 signaling is linked with IL-17 signaling by GSK3 and C/EBP $\beta$. AZD5363 inhibits Akt activation, thus enhancing GSK3 activity and subsequently diminishing IL-17-induced gene expression by inhibiting C/EBP $\beta$ function.

though a previous study suggested that it might be phosphorylation of $\mathrm{C} / \mathrm{EBP} \beta$ by GSK3, which inhibits the transcription function of C/EBP $\beta$ (21). As shown in Figure 5, IL-17 acts through the IL-17RA:IL-17RC receptor complex to activate Act1-TRAF6TAK1-IKK signaling cascade, thus activating NF- $\kappa$ B transcription factor and subsequently activating $\mathrm{C} / \mathrm{EBP} \beta$ transcription factors. NF- $\kappa \mathrm{B}$ and $\mathrm{C} / \mathrm{EBP} \beta$ transcription factors are required for initiation of transcription of the downstream target genes such as $I L-6$, Cxcl1, and Ccl20. Insulin and IGF1 bind to their receptors and activate PI3K/Akt pathway; Akt phosphorylates GSK3B at serine 9 and GSK3A at serine 21 to inhibit GSK3 activity; GSK3 phosphorylates $\mathrm{C} / \mathrm{EBP} \beta$ at threonine 179 after a priming phosphorylation at threonine 188 by ERK1/2, thus inhibiting C/EBP $\beta$ 's transcription function. Therefore, insulin/IGF1 signaling is linked with IL-17 signaling by GSK3 and C/EBP $\beta$. AZD5363 inhibits Akt activation, thus enhancing GSK3 activity and subsequently diminishing IL-17-induced gene expression by inhibiting C/EBP $\beta$ function.

Manipulation of the crosstalk between insulin/IGF1 and IL-17 is potentially significant in obese population. It has been reported 
that serum and tissue levels of IL-17 are increased in obese mice $(37,38)$ and humans $(39)$. Interestingly, serum levels of insulin and IGF1 are also increased in obese population, which together with IL-17, may be the underlying cause of the chronic inflammatory state with increased serum levels of inflammatory mediators TNF $\alpha$ and IL- $6(8,40)$. Obesity has been associated with increased risks of breast cancer, endometrial cancer, esophageal adenocarcinoma, pancreas cancer, colorectal cancer, renal cancer, thyroid cancer, gallbladder cancer, and prostate cancer (41-49). Chronic inflammation in obesity is suspected as one of the possible mechanisms underlying the increased cancer risk. In our previous study, we found that melatonin can block the crosstalk between insulin/IGF1 and IL-17 through inhibition of Akt function (8). In the present study, we found that AZD5363, a pan-Akt inhibitor, can do the same. AZD5363 reduced phosphorylation of GSK3 $\alpha$ at serine 21 and GSK3 $\beta$ at serine 9, thus increasing the enzyme activities of GSK $3 \alpha$ and GSK3 $\beta$, and subsequently represses IL-17-induced gene expression. Preclinical studies have shown that AZD5363 may be effective in inhibiting tumor growth (27), yet it remains to be determined whether AZD5363 may alter the inflammatory microenvironment in the tumors and how this contributes to the anti-tumor function of AZD5363.

Interestingly, we observed that AZD5363, a pan-Akt inhibitor, increased the P-Akt levels in wild-type, GSK3 $\alpha^{-1-}$ and GSK3 $\beta^{-1-}$ MEF cells. In general, phosphorylated Akt is the activated form of Akt (30). However, it has been reported that several Akt inhibitors elevate the levels of P-Akt. The mechanism behind this may be that suppression of S6K (p70S6K) activity stabilizes IRS-1 and increases IRS-1 adapter protein levels, which in turn induces Akt activity (50-54). Another possible cause of the hyperphosphorylation is that the Akt inhibitor sensitizes the pleckstrin homology (PH) domain to bind basal levels of PIP3 to facilitate membrane localization and induce conformational change of Akt to become more susceptible to kinase phosphorylation or less susceptible to phosphatase dephosphorylation (55). Of note, the increase of PAkt and total Akt was less obvious in the mouse prostate tissues, compared to the MEFs upon AZD5363 treatment. We speculate that this might be due to that the prostate glandular tissues responded differently from the MEFs. But the exact reason is not clear.

In summary, this study indicates that insulin and IGF1 can enhance IL-17-induced inflammatory responses through suppression of GSK3 function by phosphorylation of GSK3 $\alpha$ and GSK3 $\beta$. AZD5363 inhibits Akt function and thus inhibits the synergy between IL-17 and insulin/IGF1 through enhancing GSK3 function by reducing phosphorylation of GSK3 $\alpha$ and GSK3 $\beta$. These findings imply that the cooperative crosstalk of IL-17 and insulin/IGF1 in initiating inflammatory responses may be alleviated by AZD5363.

\section{AUTHOR CONTRIBUTIONS}

Chong Chen performed the experiments, analyzed the data, and prepared the manuscript. Qiuyang Zhang, Mark Lambrechts, Sen Liu, and Yine Qu participated in the experiments and analysis of data. Zongbing You conceived and designed the work, analyzed the data, and prepared the manuscript. All authors critically revised the manuscript, approved the final version, and agreed to be accountable for all aspects of the manuscript.

\section{ACKNOWLEDGMENTS}

The authors thank Dr. James R. Woodgett (Mount Sinai Hospital and the Samuel Lunenfeld Research Institute, Toronto, ON, Canada M5G1X5) for providing the wild-type, GSK3 $\alpha^{-1-}$, and GSk3 $\beta^{-1-}$ MEF cells. The core facilities of Tulane Cancer Center and Louisiana Cancer Research Consortium were used in this study. This work was supported in whole or in part by National Institutes of Health (P20GM103518 and R01CA174714), by Department of Defense Health Program through the Prostate Cancer Research Program (W81XWH-14-1-0050, W81XWH14-1-0149, and W81XWH-14-1-0458; the U.S. Army Medical Research Acquisition Activity, 820 Chandler Street, Fort Detrick MD 21702-5014 is the awarding and administering acquisition office), and by the Developmental Fund of Tulane Cancer Center (TCC) and Louisiana Cancer Research Consortium (LCRC) Fund. The content of this article is solely the responsibility of the authors and does not necessarily represent the official views of the National Institutes of Health or the Department of Defense.

\section{REFERENCES}

1. Kolls JK, Linden A. Interleukin-17 family members and inflammation. Immunity (2004) 21(4):467-76. doi:10.1016/j.immuni.2004.08.018

2. Novatchkova M, Leibbrandt A, Werzowa J, Neubuser A, Eisenhaber F. The STIRdomain superfamily in signal transduction, development and immunity. Trends Biochem Sci (2003) 28(5):226-9. doi:10.1016/S0968-0004(03)00067-7

3. Chang SH, Park H, Dong C. Actl adaptor protein is an immediate and essential signaling component of interleukin-17 receptor. J Biol Chem (2006) 281(47):35603-7. doi:10.1074/jbc.C600256200

4. Qian Y, Liu C, Hartupee J, Altuntas CZ, Gulen MF, Jane-Wit D, et al. The adaptor Act1 is required for interleukin 17-dependent signaling associated with autoimmune and inflammatory disease. Nat Immunol (2007) 8(3):247-56. doi:10.1038/ni1439

5. Maitra A, Shen F, Hanel W, Mossman K, Tocker J, Swart D, et al. Distinct functional motifs within the IL-17 receptor regulate signal transduction and target gene expression. Proc Natl Acad Sci U S A (2007) 104(18):7506-11. doi:10.1073/pnas.0611589104

6. Ho AW, Shen F, Conti HR, Patel N, Childs EE, Peterson AC, et al. IL-17RC is required for immune signaling via an extended SEF/IL-17R signaling domain in the cytoplasmic tail. J Immunol (2010) 185(2):1063-70. doi:10.4049/jimmunol. 0903739

7. Liu C, Qian W, Qian Y, Giltiay NV, Lu Y, Swaidani S, et al. Act1, a Ubox E3 ubiquitin ligase for IL-17 signaling. Sci Signal (2009) 2(92):ra63. doi:10.1126/scisignal.2000382

8. Ge D, Dauchy RT, Liu S, Zhang Q, Mao L, Dauchy EM, et al. Insulin and IGF1 enhance IL-17-induced chemokine expression through a GSK3B-dependent mechanism: a new target for melatonin's anti-inflammatory action. J Pineal Res (2013) 55(4):377-87. doi:10.1111/jpi.12084

9. Zhu S, Pan W, Song X, Liu Y, Shao X, Tang Y, et al. The microRNA miR-23b suppresses IL-17-associated autoimmune inflammation by targeting TAB2, TAB3 and IKK-alpha. Nat Med (2012) 18(7):1077-86. doi:10.1038/nm.2815

10. Hwang SY, Kim JY, Kim KW, Park MK, Moon Y, Kim WU, et al. IL-17 induces production of IL-6 and IL-8 in rheumatoid arthritis synovial fibroblasts via NF-kappaB- and PI3-kinase/Akt-dependent pathways. Arthritis Res Ther (2004) 6(2):R120-8. doi:10.1186/ar1038

11. Bulek K, Liu C, Swaidani S, Wang L, Page RC, Gulen MF, et al. The inducible kinase IKKi is required for IL-17-dependent signaling associated with neutrophilia and pulmonary inflammation. Nat Immunol (2011) 12(9):844-52. doi:10.1038/ni.2080

12. Sun D, Novotny M, Bulek K, Liu C, Li X, Hamilton T. Treatment with IL-17 prolongs the half-life of chemokine CXCL1 mRNA via the adaptor TRAF5 and 
the splicing-regulatory factor SF2 (ASF). Nat Immunol (2011) 12(9):853-60. doi:10.1038/ni.2081

13. Baxter RC, Bryson JM, Turtle JR. Somatogenic receptors of rat liver: regulation by insulin. Endocrinology (1980) 107(4):1176-81. doi:10.1210/endo-107-4- 1176

14. Gallagher EJ, LeRoith D. The proliferating role of insulin and insulin-like growth factors in cancer. Trends Endocrinol Metab (2010) 21(10):610-8. doi:10.1016/j. tem.2010.06.007

15. Cross DA, Alessi DR, Cohen P, Andjelkovich M, Hemmings BA. Inhibition of glycogen synthase kinase- 3 by insulin mediated by protein kinase B. Nature (1995) 378(6559):785-9. doi:10.1038/378785a0

16. Cross DA, Alessi DR, Vandenheede JR, McDowell HE, Hundal HS, Cohen P. The inhibition of glycogen synthase kinase- 3 by insulin or insulin-like growth factor 1 in the rat skeletal muscle cell line L6 is blocked by wortmannin, but not by rapamycin: evidence that wortmannin blocks activation of the mitogenactivated protein kinase pathway in L6 cells between Ras and Raf. Biochem J (1994) 303(Pt 1):21-6.

17. Chiara F, Rasola A. GSK-3 and mitochondria in cancer cells. Front Oncol (2013) 3:16. doi:10.3389/fonc.2013.00016

18. Ruddy MJ, Wong GC, Liu XK, Yamamoto H, Kasayama S, Kirkwood KL, et al. Functional cooperation between interleukin-17 and tumor necrosis factor-alpha is mediated by CCAAT/enhancer-binding protein family members. J Biol Chem (2004) 279(4):2559-67. doi:10.1074/jbc.M308809200

19. Shen F, Hu Z, Goswami J, Gaffen SL. Identification of common transcriptional regulatory elements in interleukin-17 target genes. J Biol Chem (2006) 281(34):24138-48. doi:10.1074/jbc.M604597200

20. Shen F, Li N, Gade P, Kalvakolanu DV, Weibley T, Doble B, et al. IL-17 receptor signaling inhibits C/EBPbeta by sequential phosphorylation of the regulatory 2 domain. Sci Signal (2009) 2(59):ra8. doi:10.1126/scisignal.2000066

21. Demarchi F, Bertoli C, Sandy P, Schneider C. Glycogen synthase kinase-3 beta regulates NF-kappa B1/p105 stability. J Biol Chem (2003) 278(41):39583-90. doi:10.1074/jbc.M305676200

22. Toren P, Kim S, Cordonnier T, Crafter C, Davies BR, Fazli L, et al. Combination AZD5363 with enzalutamide significantly delays enzalutamide-resistant prostate cancer in preclinical models. Eur Urol (2014). doi:10.1016/j.eururo. 2014.08.006

23. Lamoureux F, Thomas C, Crafter C, Kumano M, Zhang F, Davies BR, et al. Blocked autophagy using lysosomotropic agents sensitizes resistant prostate tumor cells to the novel Akt inhibitor AZD5363. Clin Cancer Res (2013) 19(4):833-44. doi:10.1158/1078-0432.CCR-12-3114

24. Yung HW, Charnock-Jones DS, Burton GJ. Regulation of AKT phosphorylation at Ser473 and Thr308 by endoplasmic reticulum stress modulates substrate specificity in a severity dependent manner. PLoS One (2011) 6(3):e17894. doi:10.1371/journal.pone.0017894

25. Altomare DA, Testa JR. Perturbations of the AKT signaling pathway in human cancer. Oncogene (2005) 24(50):7455-64. doi:10.1038/sj.onc. 1209085

26. Bellacosa A, Kumar CC, Di Cristofano A, Testa JR. Activation of AKT kinases in cancer: implications for therapeutic targeting. Adv Cancer Res (2005) 94:29-86. doi:10.1016/S0065-230X(05)94002-5

27. Davies BR, Greenwood H, Dudley P, Crafter C, Yu DH, Zhang J, et al. Preclinical pharmacology of AZD5363, an inhibitor of AKT: pharmacodynamics, antitumor activity, and correlation of monotherapy activity with genetic background. Mol Cancer Ther (2012) 11(4):873-87. doi:10.1158/1535-7163.MCT-11-0824-T

28. Alessi DR, Andjelkovic M, Caudwell B, Cron P, Morrice N, Cohen P, et al. Mechanism of activation of protein kinase B by insulin and IGF-1. EMBO J (1996) 15(23):6541-51.

29. Alessi DR, James SR, Downes CP, Holmes AB, Gaffney PR, Reese CB, et al. Characterization of a 3-phosphoinositide-dependent protein kinase which phosphorylates and activates protein kinase B alpha. Curr Biol (1997) 7(4):261-9. doi:10.1016/S0960-9822(06)00122-9

30. Sarbassov DD, Guertin DA, Ali SM, Sabatini DM. Phosphorylation and regulation of $\mathrm{Akt} / \mathrm{PKB}$ by the rictor-mTOR complex. Science (2005) 307(5712):1098-101. doi:10.1126/science.1106148

31. Hoeflich KP, Luo J, Rubie EA, Tsao MS, Jin O, Woodgett JR. Requirement for glycogen synthase kinase-3beta in cell survival and NF-kappaB activation. Nature (2000) 406(6791):86-90. doi:10.1038/35017574

32. Chen C, Khismatullin DB. Lipopolysaccharide induces the interactions of breast cancer and endothelial cells via activated monocytes. Cancer Lett (2014) 345(1):75-84. doi:10.1016/j.canlet.2013.11.022
33. Couzin-Frankel J. Inflammation bares a dark side. Science (2010) 330(6011):1621. doi:10.1126/science.330.6011.1621

34. Coussens LM, Werb Z. Inflammation and cancer. Nature (2002) 420(6917):860-7. doi:10.1038/nature01322

35. Zhang Q, Liu S, Ge D, Xue Y, Xiong Z, Abdel-Mageed AB, et al. Interleukin17 promotes formation and growth of prostate adenocarcinoma in mouse models. Cancer Res (2012) 72(10):2589-99. doi:10.1158/0008-5472.CAN-113795

36. Zhang Q, Liu S, Xiong Z, Wang AR, Myers L, Melamed J, et al. Interleukin17 promotes development of castration-resistant prostate cancer potentially through creating an immunotolerant and pro-angiogenic tumor microenvironment. Prostate (2014) 74(8):869-79. doi:10.1002/pros.22805

37. Winer S, Paltser G, Chan Y, Tsui H, Engleman E, Winer D, et al. Obesity predisposes to Th17 bias. Eur J Immunol (2009) 39(9):2629-35. doi:10.1002/eji. 200838893

38. Pini M, Fantuzzi G. Enhanced production of IL-17A during zymosan-induced peritonitis in obese mice. J Leukoc Biol (2010) 87(1):51-8. doi:10.1189/jlb. 0309188

39. Sumarac-Dumanovic M, Stevanovic D, Ljubic A, Jorga J, Simic M, StamenkovicPejkovic D, et al. Increased activity of interleukin-23/interleukin-17 proinflammatory axis in obese women. Int J Obes (Lond) (2009) 33(1):151-6. doi:10.1038/ijo.2008.216

40. Cohen DH, LeRoith D. Obesity, type 2 diabetes, and cancer: the insulin and IGF connection. Endocr Relat Cancer (2012) 19(5):F27-45. doi:10.1530/ERC11-0374

41. Stephenson GD, Rose DP. Breast cancer and obesity: an update. Nutr Cancer (2003) 45(1):1-16. doi:10.1207/S15327914NC4501_1

42. Kaaks R, Lukanova A, Kurzer MS. Obesity, endogenous hormones, and endometrial cancer risk: a synthetic review. Cancer Epidemiol Biomarkers Prev (2002) 11(12):1531-43.

43. Chen Q, Zhuang H, Liu Y. The association between obesity factor and esophageal caner. J Gastrointest Oncol (2012) 3(3):226-31. doi:10.3978/j.issn.2078-6891. 2012.026

44. Bracci PM. Obesity and pancreatic cancer: overview of epidemiologic evidence and biologic mechanisms. Mol Carcinog (2012) 51(1):53-63. doi:10.1002/mc. 20778

45. Moghaddam AA, Woodward M, Huxley R. Obesity and risk of colorectal cancer: a meta-analysis of 31 studies with 70,000 events. Cancer Epidemiol Biomarkers Prev (2007) 16(12):2533-47. doi:10.1158/1055-9965.EPI-07-0708

46. Chow WH, Gridley G, Fraumeni JF Jr, Jarvholm B. Obesity, hypertension, and the risk of kidney cancer in men. N Engl J Med (2000) 343(18):1305-11. doi:10.1056/NEJM200011023431804

47. Kitahara CM, Platz EA, Freeman LE, Hsing AW, Linet MS, Park Y, et al. Obesity and thyroid cancer risk among U.S. men and women: a pooled analysis of five prospective studies. Cancer Epidemiol Biomarkers Prev (2011) 20(3):464-72. doi:10.1158/1055-9965.EPI-10-1220

48. Larsson SC, Wolk A. Obesity and the risk of gallbladder cancer: a meta-analysis. Br J Cancer (2007) 96(9):1457-61. doi:10.1038/sj.bjc.6603703

49. Amling CL, Riffenburgh RH, Sun L, Moul JW, Lance RS, Kusuda L, et al. Pathologic variables and recurrence rates as related to obesity and race in men with prostate cancer undergoing radical prostatectomy. J Clin Oncol (2004) 22(3):439-45. doi:10.1200/JCO.2004.03.132

50. Shah OJ, Wang Z, Hunter T. Inappropriate activation of the TSC/Rheb/mTOR/ S6K cassette induces IRS1/2 depletion, insulin resistance, and cell survival deficiencies. Curr Biol (2004) 14(18):1650-6. doi:10.1016/j.cub.2004.08.026

51. Manning BD, Logsdon MN, Lipovsky AI, Abbott D, Kwiatkowski DJ, Cantley LC. Feedback inhibition of Akt signaling limits the growth of tumors lacking Tsc2. Genes Dev (2005) 19(15):1773-8. doi:10.1101/gad.1314605

52. Um SH, Frigerio F, Watanabe M, Picard F, Joaquin M, Sticker M, et al. Absence of S6K1 protects against age- and diet-induced obesity while enhancing insulin sensitivity. Nature (2004) 431(7005):200-5. doi:10.1038/ nature 02866

53. Harrington LS, Findlay GM, Gray A, Tolkacheva T, Wigfield S, Rebholz H, et al. The TSC1-2 tumor suppressor controls insulin-PI3K signaling via regulation of IRS proteins. J Cell Biol (2004) 166(2):213-23. doi:10.1083/jcb.200403069

54. O'Reilly KE, Rojo F, She QB, Solit D, Mills GB, Smith D, et al. mTOR inhibition induces upstream receptor tyrosine kinase signaling and activates Akt. Cancer Res (2006) 66(3):1500-8. doi:10.1158/0008-5472.CAN-05-2925 
55. Okuzumi T, Fiedler D, Zhang C, Gray DC, Aizenstein B, Hoffman R, et al. Inhibitor hijacking of Akt activation. Nat Chem Biol (2009) 5(7):484-93. doi:10.1038/nchembio. 183

Conflict of Interest Statement: The authors declare that the research was conducted in the absence of any commercial or financial relationships that could be construed as a potential conflict of interest.

Received: 22 September 2014; paper pending published: 04 November 2014; accepted: 17 November 2014; published online: 01 December 2014
Citation: Chen C, Zhang Q, Liu S, Lambrechts M, Qu Y and You Z (2014) AZD5363 inhibits inflammatory synergy between interleukin-17 and insulin/insulin-like growth factor 1. Front. Oncol. 4:343. doi: 10.3389/fonc.2014.00343

This article was submitted to Surgical Oncology, a section of the journal Frontiers in Oncology.

Copyright (c) 2014 Chen, Zhang, Liu, Lambrechts, Qu and You. This is an open-access article distributed under the terms of the Creative Commons Attribution License (CC $B Y)$. The use, distribution or reproduction in other forums is permitted, provided the original author(s) or licensor are credited and that the original publication in this journal is cited, in accordance with accepted academic practice. No use, distribution or reproduction is permitted which does not comply with these terms. 